\title{
Analyzing the potential and the load evaluation on Ubrug hydro power plant of Sukabumi, West Java
}

\author{
Didik Notosudjono $^{1, *}$, Evita Wismiana ${ }^{1}$, Fitrah Alamsyah ${ }^{1}$, Bagus Dwi Ramadhon ${ }^{2}$ \\ ${ }^{1}$ Pakuan University, Jl. Pakuan PB No.452 Bogor, Indonesia \\ ${ }^{2}$ Brawijaya University, Jl. MT Haryono 66, Malang, Indonesia
}

\begin{abstract}
Built in 1923, the Ubrug Hydro Power Plant in Sukabumi was set up with an installed power of 5,94 MW on 1st unit and 2nd unit and 6,48 MW on the 3rd unit resulting in sum total of 18,36 MW. However, at present, the actual total power only generates $15,045 \mathrm{MW}$, a smaller number than its initial capacity, due to the lack of water discharge. Based on the measurement data, the load of the generator has experienced a decrease of power in normal field operation with a peak load of 9,5 MW and the lowest of 6 MW. On daily operations, only 2 generators are being operated, leaving the 3rd generator unoperated. This is due to the aging hydroelectric power plant on the location and the transition of forest functions in the upstream area, that serves as water absorption, to settlements of residents, and industrial estates. The other and the most salient cause is the waste carried by the Cicatih River coming along with the flow of water in the conduit.
\end{abstract}

\section{Introduction}

Hydropower energy is one type of a renewable energy resource which is produced by the motion of water through hydropower device and aims to generate electricity. When the water flows due to the force of gravity, its potential energy converts into kinetic energy. This kinetic energy of the flowing water subsequently turns blades or vanes in the hydro turbines, resulting in the energy being transformed into mechanical energy. The turbine turns the generator rotor which converts this mechanical energy into electrical energy. [3] Many other components may be used in a hydropower system to produce energy which presumably is the earliest type of renewable energy technique [1].

According to the power generation capacity, the Hydro power is classified into several types, namely large hydro power, medium hydro power, and small hydro power as explained in the following figures.

- Large hydro power: $>100 \mathrm{MW}$

- Medium hydro power: 30-100 MW

- Small hydro power: 1-30 MW

Some hydro plants designated for a very small scale purpose are also available and classified into Mini hydro power engaging a capacity between $100 \mathrm{~kW}$ to $1 \mathrm{MW}$ and Micro hydro up to $100 \mathrm{~kW}$. These are generally used to meet the need of a small community or rural industry where grid is not available [2]

The Ubrug Hydroelectric Power Plant built in 1923 is equipped with installed power of $18.36 \mathrm{MW}$ and three generator units that are driven by three water turbines.

The result of the study of Hydro Power Ubrug, Sukabumi would help the Government review the already 90 -year-old hydro power policy in Indonesia. In this case, the ouput of Hydro power and its potential have substantially decreased, as happens to the Hydro power in Ubrug, Sukabumi, which potentially generates output of $15,045 \mathrm{MW}$ for three Generators, whereas in fact only two Generators work.

\section{Methodology}

The methods used in this analysis consist of:

a. Literature Study, where the authors study and collect data during the accomplishment of the Performance Studies of Sukabumi's Ubrug power plant as a case study, whereas the theoretical data is drawn from the referential books in the library, the relevant documents, and the scientific web site in the internet as well as other various sources.

b. Data Measurement, in which the Water Discharge (Q), height $(\mathrm{h})$ and Potential Hydroelectric Ubrug are directly calculated and the Generator Load is measured by utilizing the existing measuring equipment available in the hydroelectric power in Ubrug.

c. Data Analysis, by which the research focuses on how to analyze the system, based on the calculation of the relevant equations using the data which is obtained from the hydro potential and the load performance analysis of Ubrug Power Plant.

The results of the preliminary study have revealed that .decreased, without eliminating the fact that prior to 1980 , it was the Base Load which supplied energy for systems in Java Island. And, to date, due to the transition of forest function into housing and industries, the hydro power in Ubrug Sukabumi has functionally switched to a system

\footnotetext{
* Corresponding author: dnotosudjono@gmail.com
} 
aimed at overcoming peak load with a maximum of 2 generators in operation.

\section{Basic Theory}

\subsection{Generator}

The AC generator or alternating current (also known as synchronous generator/alternator) is the main source of all electrical energy utilization. The machine is the largest energy converter in the world. Generators are machines that use magnets to convert mechanical energy into electrical energy. The principle of a generator is embodied when a conductor is driven in a magnetic field and, in turn, generates an electric motion force. The generator is driven by several mechanical machines such as steam, water turbine, gasoline engine and electric motor [4].

\subsection{Hydro Power Plant}

The generation of hydro power is a form of power transformation from hydropower with a certain height and water discharge into electricity, using a water turbine and generator [5].

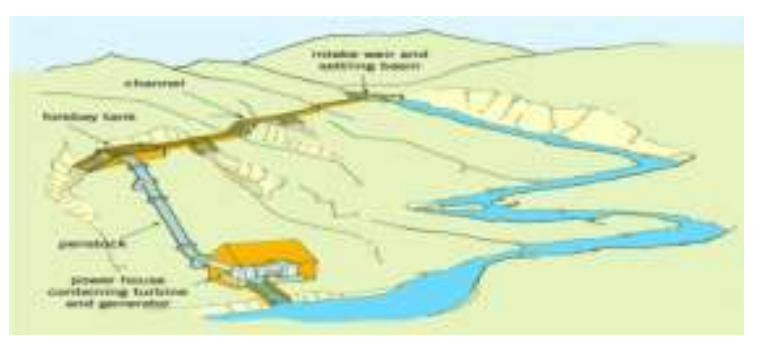

Fig 1. Run off River Hydro Power work principle [12]

\subsubsection{The calculation of output power generation from hydro turbine}

The potential in this regards refers to a description of the magnitude of the capacity of power plants that may be developed in a particular location plan. In accordance with the nature and the process or the mechanism of the generation of electrical energy derived from hydropower, there are 2 (two) main components that form the basis of the occurrence of the electricity generation, namely water discharge and water altitude (height) [6].

The output power generated from the hydro turbine (Pgen), can be estimated by the following expression [1]:

$$
P_{\text {gen }}=\rho \cdot g \cdot H_{n} \cdot Q \cdot \eta_{t} \cdot \eta_{\text {gen }}[\mathrm{W}]
$$

where $\rho=1000\left[\mathrm{~kg} / \mathrm{m}^{3}\right]$ as water density, $g=9.81\left[\mathrm{~m} / \mathrm{s}^{2}\right]$ as gravity acceleration, $\eta t[\%]$ as turbine efficiency, $\eta_{g e n}$ $[\%]$ as generator efficiency, $\mathrm{q}$ as Water Discharge $\left(\mathrm{m}^{3} / \mathrm{s}\right)$, $\mathrm{h}$ as Fall height $(\mathrm{m})$.

\subsubsection{Water Discharge}

Discharge refers to the amount of water flowing through a particular cross-section of a river per unit of time. Water discharge is determined by several factors including rainfall, geological conditions, flora, temperature, and upstream. The discharge always changes from season to season and from day to day. Below is the calculation of water discharge:

$$
\mathrm{Q}=\mathrm{V} \times \mathrm{A}
$$

Where:

$\mathrm{Q}=$ water discharge $\left(\mathrm{m}^{3} /\right.$ second $)$

$\mathrm{V}=$ water flow velocity $(\mathrm{m} /$ second $)$

$\mathrm{A}=$ river cross section area $\left(\mathrm{m}^{2}\right)$

The water discharge (Q) is the result of multiplication between the cross-sectional area (A) of the channel/stream and the water flow velocity (V) which can be identified in the equation:

$$
\mathrm{V}=\mathrm{S} / \mathrm{T}
$$

Where:

$\mathrm{V}=$ Float flow velocity $(\mathrm{m} / \mathrm{s})$

$\mathrm{S}=$ Distance from point A to point B (m)

$\mathrm{T}=$ Float reach time $(\mathrm{s})$

\subsubsection{Penstock}

Press pipes used to drain water from a head tank or directly from a water-take building to a water turbine are called Penstock. Channel pipes are the common name for the base or tunnel used for placing a penstock, anchor block and saddle, which will withstand the pipe [5].

To determine the cross-sectional area of the penstock, the equation below is used [8]:

$$
\mathrm{A}_{n}=\pi \times\left(\frac{D}{2}\right)^{2}
$$

Where:

$A_{n}=$ Penstock cross-sectional area $\left(\mathrm{m}^{2}\right)$

$\mathrm{D}=$ Pipe Diameter $(\mathrm{m})$

a. To determine the velocity of water flow inside the penstock, the equation below is used:

$$
\mathrm{V}=\left(\frac{Q}{\frac{1}{4} \pi D^{2}}\right)
$$

Where:

$\mathrm{V}=$ Flowing speed $(\mathrm{m} / \mathrm{det})$

$\mathrm{Q}=$ Flow discharge $\left(\mathrm{m}^{3} /\right.$ det $)$

$\mathrm{D}=$ Penstock diameter $(\mathrm{m})$

b. Losses on the penstock's duct due to the filter (trashrack) can be calculated using the following equation [9]:

$$
h s=k t\left(\frac{t_{k}}{b_{k}}\right)^{\frac{4}{3}} \sin \alpha \frac{V^{2}}{2 g}
$$

Where:

$\mathrm{h}_{\mathrm{s}}=$ loss of height compression filter (m)

$\mathrm{k}_{\mathrm{t}}=$ Coefficient of energy loss due to lattice shape $(0,5$

for square-shaped, 0,05 For rounded shape)

$\mathrm{t}_{\mathrm{k}}=$ lattice thickness $(\mathrm{m})$

$b_{k}=$ lattice range $(\mathrm{m})$ 
$\alpha=$ mounting angle

$\mathrm{v}=$ flow speed $(\mathrm{m} / \mathrm{s})$

$\mathrm{g}=$ gravitational acceleration $\left(9.8 \mathrm{~m} / \mathrm{s}^{2}\right)$

c. Losses on the penstock's duct due to the inclusion can be calculated using the following equation:

$$
\mathrm{hp}=\mathrm{Kx} \mathrm{V}^{2} / 2 \mathrm{~g}
$$

Where:

$\mathrm{h}_{\mathrm{p}}=$ loss of height compression due to inclusion (m)

$\mathrm{K}=$ velocity coefficient $(0,95$

d. Losses on the penstock's duct due to the water curving can be calculated using the following equation:

$$
\mathrm{hp}=\mathrm{Kb} \times \mathrm{V}^{2} / 2 \mathrm{~g}
$$

Whereas:

$\mathrm{h}_{\mathrm{b}}=$ Loss of height compression due to curving (m)

$\mathrm{K}_{\mathrm{b}}=$ Curve coefficient $\left(0,67\right.$ with a curve of $\left.50^{\circ}\right)$

\subsection{Prime Mover (Turbine)}

Hydraulic turbines, closely related to the generator, is of the main function to convert water energy into electric power. Water flows through the turbine, energizing the mover (runner) of the turbine and making it rotate. The funnel of the driver is directly related to the generator, provided that the considerable mechanical power is channeled into the generator. Thus, turbines occupy key positions in the field of hydroelectric engineering (hydroelectric) and form a large part of all generation [10].



Fig. 2. Various turbine applications

(https://yokealjauza.wordpress.com/2014/02/28/water turbine)

\section{Analysis and Discussion}

\subsection{Water Flow Velocity}

The measurement of water flow velocity is performed 3 times at each point, with a distance of 10 meters to obtain the velocity of the channel $\mathrm{V}$ (v) flow from the measurement result calculated by means of equation
(2.13). For example, in the conduit at point A, 3 experiments are performed. The experiment 1 is with a distance of 10 meters and a time (T) of 14.56 second, then:

$$
\mathrm{V}_{1}=\frac{10}{14,56}=0.686 \mathrm{~m} / \mathrm{s}
$$

So the water velocity time at point $\mathrm{A}$ in experiment 1 is $0.686 \mathrm{~m} / \mathrm{s}$. Similarly, we can calculate the water velocity at point $\mathrm{A}$ on experiment 2 and experiment 3 as follows:

$$
\begin{aligned}
& \mathrm{V}_{2}=\frac{10}{14,7 \mathrm{a}}=0.678 \mathrm{~m} / \mathrm{s} \\
& \mathrm{V}_{3}=\frac{10}{14,66}=0.682 \mathrm{~m} / \mathrm{s} .
\end{aligned}
$$

So the velocities of water at point $\mathrm{A}$ for the second and third experiment are $0.678 \mathrm{~m} / \mathrm{s}$ and $0.682 \mathrm{~m} / \mathrm{s}$ respectively. With the same method, the flow speeds at point $\mathrm{B}$ and point $\mathrm{C}$ are calculated and presented in the following Table 4.1.

Tabel.1. The Calculation Result of Water flow Velocity at an

\begin{tabular}{ccccc} 
& \multicolumn{4}{c}{ open duct } \\
\hline \multirow{2}{*}{$\begin{array}{c}\text { Experime } \\
\text { nt }\end{array}$} & Range & \multicolumn{3}{c}{ Flow Velocity $(\mathrm{m} / \mathrm{s})$} \\
\cline { 3 - 5 } & $(\mathrm{m})$ & PointA & Point B & Point C \\
\hline $\mathbf{1}$ & 10 & 0,686 & 0,683 & 0,680 \\
\hline $\mathbf{2}$ & 10 & 0,678 & 0,666 & 0,672 \\
\hline $\mathbf{3}$ & 10 & 0,682 & 0,674 & 0,691 \\
\hline
\end{tabular}

$$
\begin{aligned}
\mathrm{V}_{\mathrm{rA}} \quad=\frac{0,686+0,678+0,682}{a} & =0,682 \mathrm{~m} / \mathrm{s} \\
\mathrm{V}_{\mathrm{rB}} & =\frac{0,683+0,666+0,674}{\mathrm{a}} \\
& =0,674 \mathrm{~m} / \mathrm{s} \\
\mathrm{V}_{\mathrm{rC}} & =\frac{0,680+0,672+0,691}{a} \\
& =0.681 \mathrm{~m} / \mathrm{s}
\end{aligned}
$$

The total average velocity on the conducting duct is determined with:

$$
\begin{aligned}
\mathrm{V}_{\text {rtotal }} & =\frac{0,682+0,674+0,681}{a} \\
& =0,678 \mathrm{~m} / \mathrm{s} .
\end{aligned}
$$

In conclusion, the average water flow speed on conducting duct is $0,678 \mathrm{~m} / \mathrm{s}$.

\subsection{Sectional Water Flow Analysis}

The cross-sectional area of the conductor water channel with a base width (b) of $2 \mathrm{~m}$, the water height (h) of 2.2 $\mathrm{m}$ and the slope $(\mathrm{m})$ of $1.5 \mathrm{~m}$ is calculated by means of equation 2.5 as follows:

$$
\begin{aligned}
\mathrm{A} & =(\mathrm{b}+\mathrm{m} \cdot \mathrm{h}) \mathrm{h} \\
& =(2+1,5 \cdot 2,2) 2,2 \\
& =11.66 \mathrm{~m}^{2} .
\end{aligned}
$$

From the result, the area of water flow on the conducting duct is $11,66 \mathrm{~m}^{2}$, with a water depth of 2,2 meter. 


\subsection{Water Discharge Analysis}

After obtaining the cross-sectional area of the water channel (A) of $11.66 \mathrm{~m} 2$ and the average velocity of the conducting water channel $(\mathrm{V})$ of $0.678 \mathrm{~m} / \mathrm{s}$, the discharge channel water flow (Q) can be calculated by the following equation (2.14):

$$
\begin{aligned}
\mathrm{Q} & =\mathrm{V} \times \mathrm{A}\left(\mathrm{m}^{3} / \mathrm{s}\right) \\
& =0,678 \times 11,66 \\
& =7,905 \mathrm{~m}^{3} / \mathrm{s} .
\end{aligned}
$$

From the result, the water flow discharge happens to be $7,905 \mathrm{~m}^{3} / \mathrm{s}$. Based on the data obtained with current discharge of $10.25 \mathrm{~m}^{3} / \mathrm{s}$, such shrinkage of water discharge is visible which is due to the frequent swith functions of river upstream.

\subsection{Effective waterfall height}

The cross-sectional area for the penstock with a diameter of $1,7 \mathrm{~m}$, for both unit 1 and unit 2 as observed from the technical data can be calculated using the following equation (2.17):

$$
\begin{aligned}
A_{n} & =\pi \times\left(\frac{D}{2}\right)^{2} \\
& =3,14 \times\left(\frac{1,7}{2}\right)^{2}=2,268 \mathrm{~m}^{2} .
\end{aligned}
$$

The cross-sectional area of the penstock with a diameter of $1,7 \mathrm{~m}$ is $2,268 \mathrm{~m}^{2}$.

The water velocity inside the penstock with a water discharge of (Q) $7,905 \mathrm{~m}^{3} / \mathrm{s}$ and a diameter of $1,7 \mathrm{~m}$ can be calculated using equation (2.18) as follows:

$$
\begin{aligned}
\mathrm{V} & =\left(\frac{Q}{\frac{1}{4} \pi D^{2}}\right) \\
& =\left(\frac{7_{a} 905}{\frac{1}{4} \times 2,14 \times 11^{2} 7^{2}}\right) \\
& =\left(\frac{p_{d} 905}{2,269}\right) \\
& =3,485 \mathrm{~m} / \mathrm{s} .
\end{aligned}
$$

So, the waterflow velocity obtained is $3,485 \mathrm{~m} / \mathrm{s}$.

The losses (energy loss) inside the penstock duct which is caused by filtering (trashrack) that has the energy loss coefficient of 0.5 due to the lattice shape, lattice thickness of $0.01 \mathrm{~m}$, lattice spacing of $0.028 \mathrm{~m}$, and the $45^{\circ}$ mounting angle can be calculated by equation (2.19) provided:

$$
\begin{aligned}
& \text { ht }=k t\left(\frac{t_{k}}{b_{k}}\right)^{4 / a} \operatorname{Sin} \alpha \frac{V^{2}}{2 g} \\
& \begin{aligned}
=0,5\left(\frac{0,01}{0,028}\right)^{4 / a} & \operatorname{Sin} 45 \frac{3,485^{2}}{2 \times 9,8} \\
& =0,5 \times 0,253 \times 0,7 \times 0,619 \\
& =0,0548 \mathrm{~m} .
\end{aligned}
\end{aligned}
$$

So the losses (energy loss) inside the penstock duct due to filtering (trashrack) is $0,0548 \mathrm{~m}$.

The Losses (loss of height compression) inside the penstock duct due to water inclusion with a velocity coefficient of 0,95 can be calculated with the following equation (2.20):

$$
\begin{aligned}
\mathrm{h}_{\mathrm{p}} & =\mathrm{K} \times \frac{V^{2}}{2 g} \\
& =0,95 \times \frac{2,485^{2}}{2 \times 9,9} \\
& =0,95 \times 0,619 \\
& =0,5880 \mathrm{~m} .
\end{aligned}
$$

So the losses (energy loss) inside the penstock duct due to inclusion is $0,588 \mathrm{~m}$.

The Losses (loss of height compression) on the penstock duct due to the curving with a curve coefficient of 0,67 can be calcuted with the equation (2.21) as follows:

$$
\begin{aligned}
\mathrm{h}_{\mathrm{b}} & =\mathrm{K}_{\mathrm{b}} \times \frac{V^{2}}{2 g} \\
& =0,67 \times \frac{3,485^{2}}{2 x 9,9} \\
& =0,67 \times 0,619 \\
& =0,4147 \mathrm{~m} .
\end{aligned}
$$

So the losses (energy loss) inside the penstock duct due to curving on the pipe is $0,4147 \mathrm{~m}$.

The total height compression loss can be calculated as:

$$
\begin{aligned}
\mathrm{h}_{\text {total }} & =0,0548+0,5880+0,4147 \\
& =1,0575 \mathrm{~m} .
\end{aligned}
$$

The effective available fall height with total height $69 \mathrm{~m}$ is:

$$
\begin{aligned}
\mathrm{H}_{\mathrm{eff}} & =69-1,0575 \\
& =67,9425 \mathrm{~m} .
\end{aligned}
$$

While for unit 3 that has a size of $1,8 \mathrm{~m}$ as observed in the penstock technical data, the total height compression loss can be calculated as follows:

$$
\begin{aligned}
\mathrm{h}_{\text {total }} & =0,0435+0,4674+0,3296 \\
& =0,8405 \mathrm{~m} .
\end{aligned}
$$

So the effective available fall height with a total height of 69,4 m would be:

$$
\begin{aligned}
\mathrm{H}_{\mathrm{eff}} & =69,4-0,8405 \\
& =68,5595 \mathrm{~m} .
\end{aligned}
$$

\subsection{Power Potential}

By inserting the efficiency value of generator turbine of 0,95 , the power potential on Unit 1 would be:

$\mathrm{P}_{\mathrm{t}}=9,8 \mathrm{~m} / \mathrm{s}^{2} \times 7,905 \mathrm{~m}^{3} / \mathrm{s} \times 67,9425 \mathrm{~m} \times 0,95 \times 1000$ $\mathrm{kg} / \mathrm{m}^{3}$

$$
\begin{aligned}
& =5.000 .265,656 \mathrm{~kg} \mathrm{~m}^{2} / \mathrm{s}^{3} \\
& =5.000 .265,656 \mathrm{Joule} / \mathrm{s} \\
& =5.000 .265,656 \mathrm{Watt} \\
& =5.000,265 \mathrm{~kW} \\
& =5,000 \mathrm{MW}
\end{aligned}
$$

So the amount of power potential generated by unit 1 of turbine generator is 5,000 MW. With the same calculation method, the power potential on Unit 2 and Unit 3 can be obtained and therefore, the total power potential that can be generated at Ubrug's Hydropower plant would be:

$$
\begin{aligned}
\mathrm{P}_{\text {total }} & =\text { unit } 1+\text { unit } 2+\text { unit } 3 \\
& =5,000+5,000+5,045 \\
& =15,045 \mathrm{MW} .
\end{aligned}
$$

\subsection{Installed Power Analysis}

Theoretically, the installed power output generated by Ubrug Hydropower Plant can be calculated using equation (2.7) by referring to the nameplate or the 
technical data available on each generator and turbine at the Ubrug hydropower.

By calculating the data obtained from the nameplates or turbine technical data, the installed power of Unit 1 would be:

$$
\begin{aligned}
\mathrm{P}_{\# 1} & =\sqrt{3} \times 6.300 \mathrm{~V} \times 605 \mathrm{~A} \times 0,9 \\
& =5.941 \mathrm{~kW} \\
& =5,94 \mathrm{MW} .
\end{aligned}
$$

Thus the installed power output is 5,94 MW. With the same method, the installed power on unit 2 and unit 3 can be obtained, then

$$
\begin{aligned}
\mathrm{P}_{\text {total }} & =\text { unit } 1+\text { unit } 2+\text { unit } 3 \\
& =5,94+5,94+6,48 \\
& =18,36 \mathrm{MW} .
\end{aligned}
$$

As a result, the total power output installed on Ubrug Hydropower Plant is $18,36 \mathrm{MW}$

\subsection{Generator Load Characteristics}

From the previous analysis, it is known that the water discharge of the duct amounting to $7,905 \mathrm{~m} 3 / \mathrm{s}$ is only able to generate power potential of 15.045 MW whereas based on the preliminary data, the Ubrug Hydropower Plant is capable of generating power at the amount of $18.36 \mathrm{MW}$. Therefore the water discharge visibly shrinks.

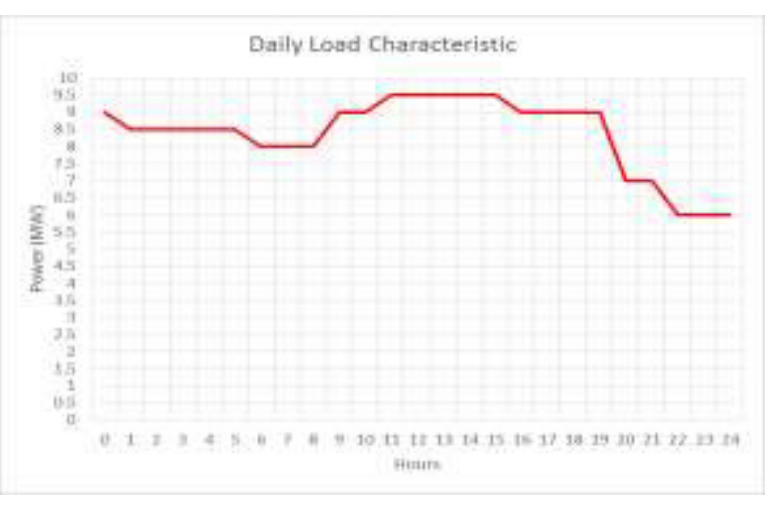

Fig.3. Daily Load Characteristic

According to data that was taken on November 3rd 2016, the peak load occurring between 11.00 - 15.00 WIB (Indonesian Western Time) was 9,5 MW. This was caused by the increase of water discharge in those hours, with 2 units of generators in operation. The lowest load of $6 \mathrm{MW}$ occurred at $22.00-24.00$ WIB. The following graph (figure 6.1) may help to describe the daily load characteristic.

Based on the observation in the field, the Generator in Ubrug hydro power evidently never fully operates that it only does with a maximum of 2 generators due to lack of water.

\subsection{Performance Study on Ubrug Hydropower Plant}

In the analysis made to calculate the performance of Ubrug Hydropower, a comparison is made between the potentially generated power, the measured power on turbine performance, and the installed power on the generating unit. The performance on each unit is mostly affected by the aging machines and the lack of water discharge.

The following contains the load comparison of each generating unit.

\subsubsection{Performance comparison on Unit 1}

The following is the daily load comparison of Unit 1.

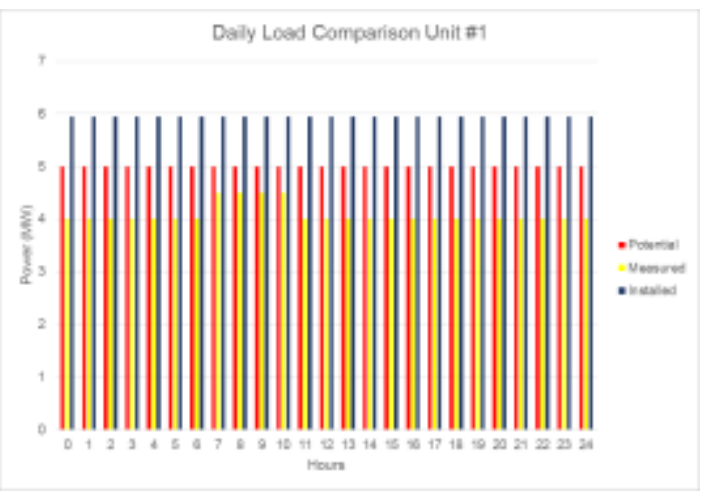

Fig.4. Daily load on Unit 1

Based on the graph in figure 7.1, on December 19th 2016, the observation focused only on Unit 1 daily load while Unit 2 and Unit 3 were unoperated. The amount of power at $00.00 \mathrm{WIB}$ was $4 \mathrm{MW}$ and it lasted until $06.00 \mathrm{WIB}$. At $07.00 \mathrm{WIB}$, the power increased to $4,5 \mathrm{MW}$ due to increase of water level. The power state of 4,5 MW lasted until 10.00 WIB. At 11.00 WIB, the power dropped back to $4 \mathrm{MW}$, because the water level decreased, and lasted in such a state until 00.00 WIB.

\subsubsection{Performance Comparison on Unit 2}

The following is the daily load comparison of Unit 2.

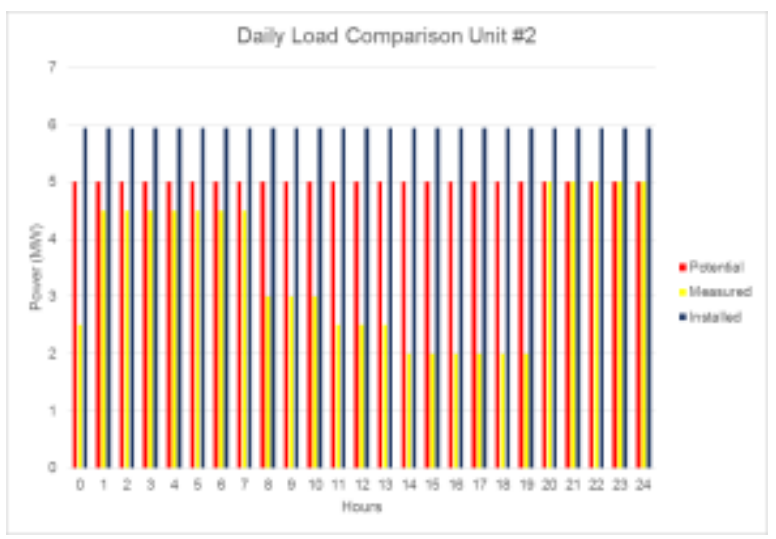

Fig.5. Daily load on Unit 2

Based on the graph in figure 7.2 which is derived from the data taken on November 23, 2016, the amount of power at $00.00 \mathrm{WIB}$ was $2,5 \mathrm{MW}$ because the water level was experiencing a decrease. At $07.00 \mathrm{WIB}$, the power load increased to 4,5 MW following the increase of water level. This amount lasted until 07.00 WIB. At 08.00 WIB the 
amount of power decreased to $3 \mathrm{MW}$ due to the decrease of water level.

\subsubsection{Performance Comparison on Unit 3}

The following is the daily load comparison of Unit 3.

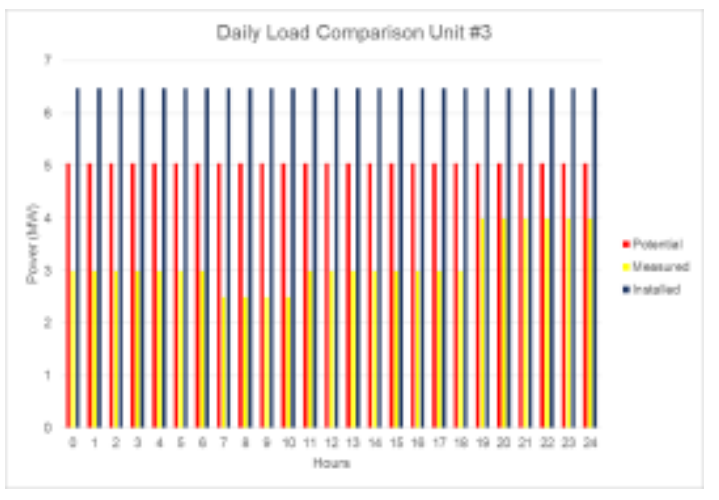

Fig.6. Daily Load on Unit 3

The graph in figure 7.3 above indicates the daily load comparison of Unit 3 which was taken on November 23rd 2016. At $00.00 \mathrm{WIB}$, the output power was $3 \mathrm{MW}$ and lasted until 06.00 WIB. At 07.00 WIB, the power decreased to 2,5 MW due to decrease of water level and lasted until 10.00 WIB. At 11.00 WIB, the power increased to $3 \mathrm{MW}$ and to $4 \mathrm{MW}$ at the following hours until 00.00 WIB.

\section{Conclusion}

Based on the study result of Ubrug Hydroelectric power plant in Sukabumi, it can be concluded that:

1. The capacity of unit 1 and unit 2 is $5,94 \mathrm{MW}$ for each, and that of unit 3 is $6,48 \mathrm{MW}$ resulting in total power of 18,36 MW. However only 2 units are separately operated due to the limited amount of water.

2. The calculation of the potential power has revealed that the power which can individually be generated by Unit 1 and Unit 2 is $5 \mathrm{MW}$ whereas it is 5,04 by Unit 3 resulting in total power of $15,045 \mathrm{MW}$. This figure is smaller than $18,36 \mathrm{MW}$ installed power, due to lack of water discharge. Based on the analysis, the amount of water discharge in Cicatih River is only powerful to move 2 turbines in Ubrug Hydropower Plant. This is due to the frequent switching functions of the Forest in the Hydro power area into housing and Industries. Thus, the Government should issue a Policy that designates the catchment area in the forest around Ubrug Hydro Power, Sukabumi, to be a protected forest. This policy is very important to maintain the availability of water debit for Hydro power and restore the forest function so that the output power will potentially be improved.

3. From the performance analysis, the measured power is evidently lesser than the potential power and installed power. There is also data that indicates equal measured power to that of the potential power. This is due to the aging machine, the forest area in the upstream which is mostly converted into residential areas, and industrial areas, and most importantly, the wastes which are carried by the Cicatih River.

\section{References}

1. Shpetim Lajqi, Naser Lajqi, Beqir Hamidi, Design and Construction of Mini Hydropower Plant with Propeller Turbine.International Journal, contemporary,Energy, vol 2, No1. pp.1 and 4. 2016 ,

2. Roshni Bhoi, Dr. S.M. Ali, Potential of Hydro Power Plant in India and its Impact on Environment, International journal Engineering Trends and Technology (IJETT), volume 10 number 3, p.114, April 2014

3. Celso Penche Layman's guidebook on how to develop a small hydro site", Published by the European Small Hydropower Association (ESHA), Second edition, Belgium, June, 1998

4. Petruzella, Frank D. Elektronik Industri. Andi. Yogyakarta.p.311, 2002

5. Arismunandar, Artono. Dr dan Kuwahara Susumu. Dr. T,Electrical Engineering,volume 1, Water Power Engineering PT Pradnya Paramita. Jakarta.p.1 and p.44, 2004

6. Sebayang, Sedya. Ir. Evalution of Mini Hidro Power Bandung. p.3. 2002

7. Marsudi, Djiteng. Ir. Electric Power Generation. Erlangga. Jakarta.p.88 2005

8. Almahali, Jalaludin. Evaluation Hidro power in Ubrug Sukabumi Pakuan University Bogor.p.88, 2009

9. Setyo Putro, Yogi Suryo. Studi Planning of Micro Hydro Power in Sungai Atei desa Tumbang Atei , Distric Sanamang Province central of Kalimantan Universitas Brawijaya. 2016

10. Dandekar.M.M. dan Sharma. K.N. Electrical Power Generation. University of Indonesia, pp.391. 1991

11. https://yokealjauza.wordpress.com/2014/02/28/wate $r$ turbine

12. http://sites.uoit.ca/sustainabilitytoday/blogposts/blog-posts/2014/09/Capturing-the-power-ofwater.php 